\title{
A New Chapter for Optical Engineering: Introducing Patent Reviews and a New Editor-in-Chief
}

\author{
Adam Wax \\ Editor-in-Chief
}

On Jan. 1, Michael Eismann completed his term as editor-in-chief of Optical Engineering (OE) and the reins were handed to me. Michael has certainly made a strong impact on the journal, and it is somewhat daunting to try and fill his shoes. However, I have always enjoyed taking on challenging projects, and I am excited to be leading this flagship journal into a new era.

I have been involved with SPIE since late last century, which is a fun way to say that I've been an SPIE member since the 1990s. My first exposure was through the Photonics West conference, which was a bit smaller than it is now, back when it was still held in San Jose. My research area was still an up-and-coming field, then called "biomedical optics" since the term "biophotonics" had not been coined yet. My first exposure to OE was in 1996. At the time, the editor-in-chief was Brian Thompson, and he declared "the time has come" as he stepped down from the leadership post.

A lot has changed in journal publishing since then. Peer review used to be conducted by paper copies sent by mail. It wasn't unusual for months to go by before hearing a response. Now peer review is all electronic, responses are expected in days, and I am pleased to say that at $\mathrm{OE}$ the average time to decision is only five weeks and publication then occurs a mere two weeks later. Students would often run to the library when new journal issues came out and eagerly photocopy articles to read later. I remember keeping stacks of paper copies on my desk ranging from those that I had pored over word by word to those I meant to get to sooner or later. Now, electronic versions and emailed tables of contents allow us to instantly read new articles or to bookmark them to read later on our tablets. My list of articles "to read later" still remains full, but at least it doesn't fill up my desk space. Open access has allowed articles to be easily read not by just those with access to university libraries but by anyone across the world with a browser and internet connection.

Now I would like to introduce the latest change in journal publishing. OE is announcing a new category of paper, the patent review. Intellectual property is an important part of the field that until recently was not closely linked to academic publishing. Citation counts often did not include patents, and yet patent citations are often a more significant indicator of technical advances, since industry often prioritizes a patent filing over an academic paper. This new paper type aims to provide perspective on areas of intellectual property for the OE readership. It will allow journal readers to appreciate the technical advances disclosed in patent filings as a complement to typical academic publications.

The patent review is meant to be a discussion of the key patents in a particular area of optical engineering. The review should discuss foundational intellectual property in a technical area, analyze the claims made in key patents and show how further patents in this domain have built upon it. These reviews should be comparable in length to typical research papers and cover topics of current interest in optical engineering.

I encourage you to consider submitting a patent review for upcoming issues of OE. If authors would like feedback on selection of topic, they are encouraged to reach out to the editorial office to talk with either myself or one of the senior editors. My expectation is that this new paper type will serve as a means to stimulate new knowledge and communication in the field. (C) The Authors. Published by SPIE under a Creative Commons Attribution 4.0 Unported License. Distribution or reproduction of this
work in whole or in part requires full attribution of the original publication, including its DOI. 